\title{
Infection: friend or foe in the development of atopy and asthma? The epidemiological evidence
}

\author{
E. von Mutius
}

Infection: friend or foe in the development of atopy and asthma? The epidemiological evidence. E. von Mutius. (C) ERS Journals Ltd 2001.

ABSTRACT: There is increasing evidence from epidemiological studies to support the "hygiene hypothesis" with regard to the development of allergic diseases. This review will discuss the epidemiological findings relating to atopy and asthma, separately.

The strongest arguments in favour of the "hygiene hypothesis" are the findings relating early life day care attendance to a significantly reduced risk of atopy and asthma, and the strong link between sibship size and the occurrence of atopy as confirmed by numerous studies.

Furthermore, data relating serological immune responses to certain infections such as hepatitis A and Toxoplasma gondii suggest a role for such infections, or alternatively the lack of hygiene, to be operative in the inhibition of the development of allergic immune responses. The effects described seem to be stronger for atopy than for asthma.

Furthermore, biological plausibility for such a hypothesis can be found from findings of recent in vitro studies and from animal experiments. Epidemiological studies attempting to identify single infections as being harmful or beneficial could fail, because it may be the total burden of microbial stimuli rather than a certain infection that directs the maturing immune system into a Th1-type T-helper cell polarized response. The timing of the exposure seems to be essential for promoting beneficial or harmful effects, and may provide a "window of opportunity".

Eur Respir J 2001; 18: 872-881.
Ludwig Maximilian Universität München, München, Germany.

Correspondence: E. von Mutius, Dr von Haunersche Kinderklinik, Ludwig Maximilian Universität München, Lindwurmstr.4, D-80337 München, Germany.

Fax: 498951604452

Keywords: Asthma

atopy

epidemiology

hygiene

infections

Received: November 22000

Accepted after revision July 272001
There have been few studies of the prevalence of allergic rhinitis and atopic eczema comparing prevalences over several areas, and although hundreds of asthma prevalence studies have been conducted in various parts of the world, these studies have rarely adopted a standardized approach. The programme of the International Study of Asthma and Allergies in Childhood (ISAAC) has eventually allowed a standardized assessment of the prevalence of self-reported symptoms of asthma, allergic rhinoconjunctivitis and atopic eczema in children throughout the world. Likewise, the European Community Respiratory Health Survey (ECRHS) has developed standardized instruments for epidemiological studies of asthma in young adults. Up to 20 -fold variations in the prevalence of self-reported symptoms of asthma, allergic rhinoconjunctivitis and atopic eczema were observed in different ISAAC centres throughout the world [1]. These worldwide variations in prevalence, and to a lesser extent the variations observed within some countries, suggest that environmental factors, in their broadest sense, may be critical in the development of these atopic conditions in childhood.

The ISAAC findings have also supported results from previous European studies showing an EastWest gradient in the prevalence of atopic conditions over Europe. Several studies performed after the fall of the communist systems have documented large differences in the prevalence of atopic diseases between East and West Europe. In West Germany, the prevalence of hay fever $(8.6 \%$ versus $2.7 \%, \mathrm{p}<0.0001)$, asthma $(9.3 \%$ versus $7.2 \%, \mathrm{p}<0.05)$ and airway hyperresponsiveness $(8.3 \%$ versus $5.5 \%, \mathrm{p}<0.0001)$ among children aged 9-11 yrs was significantly higher than the prevalence in East Germany [2]. The frequency of atopic sensitization measured by skin-prick tests in East German children was about half the rate of West German children $(18.2 \%$ versus $36.7 \%, \mathrm{p}<0.0001)$. Likewise, significantly lower prevalences of atopic sensitization were found in children aged 10-12 yrs living in Estonia and Poland, as compared to Sweden $(10.9 \%$ versus $13.6 \%$ versus $30.3 \%, p<0.0001)$ [3]. These differences were not limited to children, as they were also seen among adults living in East and West Germany [4].

\section{Atopy and asthma?}

Many hypotheses have been proposed to explain these large variations over geographical areas, including those discussing the potential role of ambient 
air pollution levels, concentrations of indoor allergens, housing conditions, nutrition, and other lifestyle factors such as family size and early childhood infections. One difficulty in assessing the role of such potential determinants for the inception of allergic and wheezing illnesses is the heterogeneity of atopic conditions. There is increasing evidence that subjects presenting with the same symptom, e.g. with wheeze, can differ markedly with respect to associated features such as the detection of immunoglobulin (Ig)-E antibodies to environmental allergens, bronchial responsiveness to direct and indirect stimuli, age of onset of the disease and response to medication [5]. Furthermore, segregation studies have shown that distinct types of atopic conditions are preferentially transmitted in families, suggesting that a parental background of hay fever is likely to increase an offspring's risk for this disease, but not necessarily for asthma and atopic eczema [6]. Likewise, the natural course of atopic conditions differs, asthma showing its peak of incidence in the first 1-4 yrs of life [7], in contrast to hay fever, which is increasingly manifest in school-age children. If the concept that a risk factor for a certain condition has to be present before the inception of the disease is to be believed, then different "windows of opportunity" for environmental exposures may be operative for certain atopic illnesses. Thereby, the timing of exposure may play a critical role when considering potential adverse or beneficial effects of environmental stimuli.

Nevertheless, a significant proportion of children with asthma produce specific IgE antibodies to environmental allergens in significant amounts. In cross-sectional and clinical studies atopic sensitization has been related to an increased prevalence of asthma, airway hyperresponsiveness and a greater severity of respiratory symptoms as compared with the absence of atopy [8-10]. This relationship between atopy and asthma weakens considerably in epidemiological studies. The population based proportion of asthma cases that are attributable to atopy has recently been estimated to be $<50 \%$ [11]. Recent analyses of the Multicentre Birth Cohort Allergy Study in Germany have shed some light on the potential link between the development of asthma and atopy. This prospective investigation, which included $>1,000$ infants enrolled at birth, measured $\operatorname{IgE}$ antibodies to food and inhalant allergens at yearly intervals from the first birthday onwards [12]. Likewise, the occurrence of wheeze was assessed at all time points up to the age of $7 \mathrm{yrs}$, at which time children also underwent bronchial challenge with histamine to measure airway responsiveness.

Sensitization to food allergens developed first, and was followed by the development of sensitivity towards inhalant allergens. Only persistent sensitization, which developed early in life as food-related IgE production and continued at school age as sensitization towards inhalant allergens, such as house dust mites, cat dander and pollen, was a strong determinant of asthma [13]. Twice as many children who were diagnosed as asthmatics or presented with airway hyperresponsiveness at $7 \mathrm{yrs}$ had had measurable $\operatorname{IgE}$ antibodies towards food allergens at the age of $1 \mathrm{yr}$, as compared to nonasthmatic children [14]. These findings suggest that some common underlying process(es) may determine both the early development of sensitization and the incidence of asthma. Risk factors for the development of asthma may, therefore, also result in an earlier onset of IgE production towards environmental allergens, most probably towards food allergens. Thus, factors enhancing the production of specific IgE antibodies, or the lack of protective mechanisms to induce tolerance towards environmental allergens early in life, might also increase the risk for asthma. Nevertheless, atopy and asthma may differ in their associations with infections, and therefore, the evidence relating to both outcomes is presented separately.

\section{Role of infections for the development of atopy}

\section{Crowding and sibship size}

The results of recent cross-sectional studies support the notion of a potential protective effect of early-life infections on the development of atopy later in childhood. There is increasing, consistent evidence that crowding [3] and particularly sibship size contributes to the expression of atopy in families. Many authors have shown that the number of siblings is inversely related to the prevalence of self-reported inhalant allergy, atopic eczema, skin test reactivity and the presence of specific IgE antibodies in the serum [15] in children, adolescents and adults. Most reports which were large enough to allow a separate analysis of the influence of older and younger siblings found a stronger relationship with the presence of older siblings than with younger brothers and sisters. In a large Australian survey, the interbirth interval to the next older sibling was also assessed [16]. For youngest children, having two siblings rather than one was associated with a significantly lower odds ratio (OR) for asthma and hay fever, and a short interbirth interval to the next older sibling was associated with a lower rate of hay fever. The consistency and strength of these associations over all age groups and different populations is intriguing and suggests a major underlying strong determinant for the responses.

Several hypotheses have been put forward to explain the sibling effect. It seems very unlikely that the age of the mother is the underlying causal factor, since in some reports the sibling effect was still seen after adjusting for the mother's age at the birth of her child. Furthermore, increasing age of the mother has been related to increasing prevalence of hay fever and skin test reactivity [17], which contrasts with the inverse relationship found for sibship size. STRACHAN [18], who first described the phenomenon in 1989 pointing towards the importance of birth order, proposed that "infection in early childhood, transmitted by unhygienic contact with older siblings, or acquired prenatally from a mother infected by contact with her older children" may prevent the development of allergic diseases. This "hygiene hypothesis" is in fact based on biological grounds and may be explained by an imbalance of different T-helper (Th) cell activation 
[19]. In much simplified terms, Th1-like T-cells produce, among other cytokines, interleukin (IL)-2 and interferon gamma (IFN- $\gamma$ ) [20]. Th2-like T-cells, in turn, produce IL-4, IL-5, IL-13 and other chemokines. IL-4 is one of the necessary signals to induce B-cell clones to switch from the production of IgM to IgE. IFN- $\gamma$, in turn, is produced in the course of viral infectious diseases and inhibits the proliferation of Th2 clones and the production of IgE by B-cells [21, 22]. Thus, a predominant activation of Th1-like $\mathrm{T}$-cells in the course of recurrent viral or bacterial infections may prevent the proliferation of Th2 clones and the development of allergic disease [20]. Although the evidence for $\mathrm{Th}$ cell polarization was initially developed in experimental mouse models, numerous clinical studies have also shown Th2 dominance with IL-4 and IL-5 overproduction in patients with hay fever, allergic bronchial asthma, and atopic dermatitis. The results were obtained using cells from peripheral blood and inflamed tissues of nose, airways and skin by employing in situ and in vitro techniques [23-25]. To better understand the concepts of the "hygiene hypothesis" also requires an appreciation of the developing immune system [26]. Th2-like cytokines are produced in the uterine environment to hamper abortion of the foetus and induce similar Th2like responses in the immature immune system of the newborn. Therefore, at birth, the neonatal immune responsiveness is distorted towards Th2-like responses. Repeated infections involving the activities of Th1-like cytokines, particularly early in life, would help T-cell immune responses to mature into a balanced phenotype, which would be less likely to favour allergen sensitization and manifestation of atopic illnesses in childhood.

\section{Day care}

Child day care may be seen as an indicator of early life exposure to numerous infectious agents. In a large, cross-sectional Norwegian study, attendance to day care was found to significantly increase the risk of upper respiratory tract infections and recurrent otitis media in 3-5-yr-old children [27]. These findings were confirmed by a recent prospective birth cohort study in Boston, MA, USA, which showed that infants attending day care centres in their first year of life are at a higher risk of developing ear infections, a runny or stuffed nose or doctor-diagnosed lower respiratory illnesses such as croup, bronchitis, bronchiolitis and pneumonia [28]. Interestingly, birth status has been shown to modify the relationship between day care and lower respiratory illness incidence. The cohort study following $>1,000$ infants up to the age of $2 \mathrm{yrs}$ and found that firstborn children who were not in day care had the lowest rate of infections [29]. The rate of lower respiratory illnesses was intermediate for children with siblings who were not in day care, and very similar for children in day care, regardless of sibling status.

Day care attendance early in life was characteristic of the former East German lifestyle. In a large crosssectional survey of East German children aged 5-14 yrs, KRÄMER et al. [30] showed that children from small families, i.e. at most three family members, entering day nursery in the first year of life were at significantly lower risk of developing hay fever and a positive skin-prick test than children attending day care after their second birthday. A recent prospective study from the USA corroborated these findings [31]. Attendance to day care in the first 6 months of life was associated with a significantly lower risk of atopy over the 13-yr follow-up period.

\section{Infections with hepatitis $A$ and measles}

Furthermore, infection with hepatitis A may be regarded as a marker of poor hygienic living conditions. A report from southern Italy showed that military recruits who were seropositive for hepatitis A had a significantly lower prevalence of atopic sensitization to common aeroallergens and a lower prevalence of atopic diseases as compared to their peers, who did not have antibodies to hepatitis A [32].

Viral and bacterial, as well as respiratory and gastrointestinal infections may exert different effects on a maturing immune system. Furthermore, it seems conceivable that only certain infections convey protection or risk depending on the nature of the infectious agent or the host's predetermined immune response. Measles and tuberculosis, two types of microbial infections which are known to be potent inducers of Th1 responses, have been particularly scrutinized in recent years. In Guinea-Bissau, West Africa, SHAHEEN et al. [33] followed children at the age of $0-6$ yrs into young adulthood. The subjects with childhood measles had about half the rate of atopic sensitization, defined as skin-prick test positivity to aeroallergens compared to those who had been vaccinated and did not acquire measles $(12.8 \%$ versus $25.6 \%$ ). The study findings should, however, be interpreted with caution since a substantial loss to follow-up occurred over time. The high mortality rate for measles, affecting $25 \%$ of the study children, further points to the hazards associated with exposure to this virus, particularly in the Third World.

Findings from high-income countries have not clearly supported the notion that measles infections may result in a reduced risk of atopy. Alm et al. [34] from Sweden showed that children from anthroposophic families, where there was a high rate of measles affecting approximately two-thirds of the study population, had a markedly reduced prevalence of atopic conditions and atopy as measured by skin-prick tests and serum IgE. However, many other environmental influences such as dietary habits and use of antibiotics also differed between anthroposophic and other Swedish families, precluding an unequivocal inference about the role of measles infections in this population. A very large Finnish study, which included half a million subjects aged 14 months to $19 \mathrm{yrs}$, related a history of measles to a history of atopic illnesses at the time of vaccination in Finland's national measlesmumps-rubella vaccination programme [35]. The investigators reported that children with a history of measles had an increased risk to develop eczema, allergic rhinitis and asthma, and this increase in risk 
was seen over all age groups, However, the authors' discovery that the risk of allergic rhinitis also increased in children aged 1-2 yrs, an age at which allergic rhinitis normally does not occur, is difficult to interpret. In a Scottish study, a history of measles infection in children $>3$ yrs was found to be inversely related to asthma prevalence at age 10-14 yrs, but not to hay fever, which was only reported from $3.7 \%$ of the teenagers, suggesting under-reporting or misclassification of allergic rhinitis [36]. Another British cross-sectional survey showed that a history of measles infection up to the age of 10 yrs was inversely related to the prevalence of hay fever, but only in children with multiple older-sibling contacts [37]. Thus, no consistent effect of measles infection on the development of atopic sensitization and hay fever was found in studies in affluent countries, contrary to the intriguing data from Guinea-Bissau.

\section{Tuberculosis}

Interest has also focused on the role of Mycobacterium tuberculosis, which is known to induce Th1-type immune responses [38, 39]. Epidemiological evidence that this immunological response is associated with a reduced risk of developing atopy comes from the study of SHIRAKAwA et al. [40]. These authors reported that, amongst Japanese school children aged 12-13 yrs, allergic and asthmatic symptoms were only one-half to one-third as common in positive tuberculin responders as in negative responders, and that remission of atopic symptoms between the ages of 7-12 yrs was 6-9 times more likely in positive tuberculin responders. The positive tuberculin responders had significantly lower levels of the Th2 cytokines IL-4, IL-10 and IL-13, and higher levels of the Th1 cytokine IFN- $\gamma$. The interpretation of these findings has been debated intensively. The inverse association between allergic status and tuberculin reactivity may simply reflect the imbalance of $\mathrm{Th} 1 / \mathrm{Th} 2$ responsiveness characteristics in atopic individuals, who have been shown to express smaller delayed type-hypersensitivity skin reactions to recall antigens than nonatopic subjects [41]. This imbalance may relate to genetic or other constitutional factors rather than to exposure to mycobacteria. However the alternative hypothesis, suggesting that exposure to $M$. tuberculosis reduces the risk of developing asthma and/or atopy, is equally conceivable. If this alternative hypothesis is correct, the reduction in the incidence of tuberculosis in many countries during this century may have contributed to the concurrent increase in the prevalence of asthma and other atopic diseases. Indeed, recent findings have inversely related tuberculosis notification rates to the prevalence of asthma, wheeze and allergic rhinitis. The study, which included participants from 23 centres of the large ISAAC study, suggested that exposure to Mycobacterium spp. may reduce the risk of childhood asthma and allergic rhinitis [42]. Some support for this notion also arises from a Finnish study, which followed verified cases of childhood and adolescent tuberculosis for 28-32 yrs and compared reimbursement rates for asthma and allergy drugs with age, sex, and geographically-matched controls [43]. Among females, tuberculosis of the respiratory tract or other organs in childhood (i.e. before 16 yrs) was associated with a significantly reduced prevalence of asthma 30 yrs later. Likewise, tuberculosis at any age was inversely related to reimbursement rates for allergic conditions in females. No such association was found for males.

Little is known with respect to a potential protective or adverse effect of other infections of the upper and lower respiratory tract. In the prospective Tucson Cohort Study, children who had nonwheezing lower respiratory tract illnesses such as pneumonia and tracheobronchitis in their first 3 yrs of life, subsequently, had reduced skin test reactivity and depressed levels of total serum IgE at the age of 6 yrs [44]. The MAtricARdi et al. [45] study of Italian military recruits found that serology to respiratory virus infections was not related to atopy. In agreement with this result, these types of infections were also unrelated to an effect on atopic sensitization in the Tucson Cohort Study [46].

\section{Gut colonization}

Microbial stimulation, both from normal commensals and pathogens through the gut, may be another route of exposure, which alters the normal intestinal colonization pattern in infancy. Thereby, the induction and maintenance of oral tolerance to innocuous antigens, such as food proteins and inhaled allergens, may be substantially hampered [47, 48]. MATRICARDI et al. [45] have recently expanded their studies; serology to Toxoplasma gondii and Helicobacter pylori in addition to hepatitis A was related to atopy in southern Italian military recruits. Seropositivity to one or more of these types of microbes showed an inverse relationship with hay fever, allergic asthma and atopy as assessed by skin-prick tests and serum IgE measurements in a dose-dependent manner. Subjects with two or more positive serology tests had approximately one-third the risk of developing atopic conditions when compared to their seronegative peers. The authors proposed that the orofaecal route of infection was a strong protective determinant for the development of atopy and atopy-related conditions.

In animal studies, colonization of the gut by normal commensals has been shown to be a prerequisite for the development of immune tolerance [46]. It remains to be seen in humans whether the early composition of the gut flora determines the processes inducing tolerance towards environmental allergens. SEPP et al. [49] have shown that the gut flora of Estonian children differs from the gut flora of Swedish infants, paralleling a marked difference in the prevalence of atopy between these regions. In 1-yr-old Estonian infants, lactobacilli were more frequently found, and the counts were higher than in the Swedish 1-yr-olds. In contrast, clostridia counts (in particular, Clostridium difficile) were higher in the Swedish infants than in the Estonian infants. These investigators expanded their studies to include the stool flora of allergic and 
nonallergic 2-yr-old children in Estonia and Sweden [50]. The allergic children in Estonia and Sweden were less often colonized with lactobacilli, as compared with the nonallergic children in the two countries. Furthermore, the proportion of aerobic micro-organisms of the intestinal flora was also higher in allergic children, whereas the proportion of anaerobes was lower as compared to nonallergic 2-yr-olds. In both studies, the number of subjects was rather low, but some indirect evidence may corroborate the notion that lactobacilli in the gut flora may play a role in the development of atopy. Firstly, populations with a higher consumption of acid-fermented vegetables, such as anthroposophic individuals or people from Estonia, have been shown to have lower rates of allergy. Secondly, preliminary findings from Finland may indicate that the administration of a strain of Lactobacillus to the diet of infants with atopic dermatitis can ameliorate the clinical manifestation of the disease [51]. The number of involved infants was low, however, and the dietary intervention was not blinded to the investigator assessing the severity of the eczema, thereby limiting the validity of these findings.

Furthermore, intestinal parasitic infections in the Third World may play a role for tolerance induction; however, the potential effects have not yet been sufficiently explored. In developed countries such as East Germany, parasitic infections are likely to be of no major importance for the reduction in the prevalence of atopic conditions seen in these areas [52].

\section{Farming environments}

A "human model" which may prove interesting in this context is the recent observation, reported by several authors, that growing up on a farm confers significant protection against the development of atopy [53-55]. In a Swiss population of schoolchildren between the ages of $6-15 \mathrm{yrs}$, the odds of having seasonal symptoms of hay fever (adjusted OR $=0.34$, 95\% CI: $0.12-0.89$ ) and of developing atopic sensitization as measured by radioallergosorbent test (RAST) (adjusted OR=0.31, 95\% CI: $0.13-0.73$ ) were strongly decreased in children raised on a farm as compared to their peers from the same rural area whose parents were not farmers [53]. Similarly, in a large survey of Bavarian children entering school at age 5-7 yrs, the prevalence of hay fever among children raised on a farm was significantly lower than that found among their peers from the same villages who did not grow up on a farm $(1.8 \%$ versus $4.9 \%, \mathrm{p}<0.001)$ [54]. Adjustment for potential confounding variables confirmed the strong inverse relationship (adjusted $\mathrm{OR}=0.52$, 95\% CI: 0.28-0.99). A recent Austrian survey of 8-10-yr-old children has confirmed the findings [55]. In all surveys, a slight protective effect was also seen for the prevalence of asthma (e.g. adjusted $\mathrm{OR}=0.65,95 \% \mathrm{CI}: 0.39-1.09$ in Bavaria); whereas, the development of atopic eczema was not affected by the farming activities of the parents.

Living conditions of farming families differ in many respects from the lifestyles of other families including larger family size, more pets, frequent heating of the family home with wood or coal, less maternal smoking, more dampness and characteristic dietary habits. None of these factors would explain the strong inverse association between atopy and growing up on a farm. In contrast, contact to livestock and poultry was found to explain much of the relationship between farming and atopy in the Austrian study [54]. Likewise, in the Bavarian survey a strong, inverse, dose-dependent relationship between exposure to livestock and the prevalence of atopic diseases was found (adjusted OR $=0.41,95 \%$ CI: $0.23-0.74$ for frequent contact to livestock) [54]. Furthermore, Austrian children with regular contact to farm animals who did not live on a farm also had a significantly lower prevalence of atopic sensitization (13.5\% versus $34.8 \%$, $\mathrm{p}=0.01$ ) when compared with children with no contact [55]. These findings suggest that factors prevalent in stables, and presumably also in the homes of farming families, confer the protection which is associated with a farming lifestyle.

\section{Endotoxin}

A potential candidate among other factors is the exposure to bacterial products such as endotoxin and lipopolysaccharides (LPS) in the stables and homes of farming families. Endotoxin concentrations have recently been shown to be higher in homes of children living on a farm as compared to homes of nonfarming families [56]. Furthermore, in families where children had regular contact with livestock, higher endotoxin concentrations were found in the children's mattresses as compared to control households. These findings suggest that contact with livestock not only strongly increases LPS exposure while staying in a stable, but also augments daily exposure indoors.

Endotoxin consists of a family of molecules (LPS), which form an intrinsic part of the outer membrane of gram-negative bacteria [57]. LPS and other bacterial wall components engage with antigen-presenting cells eliciting strong IL-12 responses [58]. IL-12, in turn, is regarded as an obligatory signal for the maturation of naive T-cells into Th1-type cells [59]. Endotoxin is ubiquitous in nature, being present in normal indoor environments as a constituent of house dust [60]. Previously, it was suggested that endotoxin levels increase where animals are kept indoors, and it seems noteworthy that several recent studies have shown a protective effect of early exposure to cats and dogs on the development of atopic sensitization [61, 62]. Furthermore, endotoxin levels are likely to be particularly high in developing countries where poultry and livestock are kept in close proximity to human housing. In this context, it is of interest to note that a previous study from Africa has found a significantly decreased OR for the development of atopic sensitization (adjusted $\mathrm{OR}=0.49$, 95\% CI: $0.28-0.87$ ) in children, in whose homes pigs were kept [33]. High exposure levels to endotoxin may, however, be a surrogate for other bacterial wall components from gram-positive bacteria or atypical mycobacteria, which are likely to affect immune responses in similar ways as LPS [63, 64]. In particular, Listeria, a germ 
also abundant in stables, is known to induce IL-12 production [65], thereby potentially deviating the immune response towards a Th1-like phenotype. Recent studies suggest that certain motifs of bacterial deoxyribonucleic acid (DNA) might also prevent the development of atopy, at least in the experimental animal model [66].

Endotoxin exposure in house dust has recently been related to the development of atopic sensitization in infants enrolled in a cohort study in the USA [67]. Among 61 children aged 9-24 months with three physician-documented wheezing episodes and low socioeconomic status, endotoxin levels in the house dust were inversely related to atopic sensitization. Interestingly, a strong relation between endotoxin exposure and IFN- $\gamma$ production by $\mathrm{CD} 4+$ and $\mathrm{CD} 8+$ cells was seen, suggesting a stimulation of the immune system towards Th1 responses by environmental levels of indoor exposure to endotoxin. The infant cohort enrolled in this study was, however, a high risk group with a history of repeated wheezing episodes. It remains to be seen whether there is a potential inhibitory effect of indoor endotoxin exposure for the development of atopy in other children.

\section{Role of infections for the development of asthma}

\section{Respiratory syncytial virus infections}

There is an ongoing debate about a potential deleterious role of viral infection, mainly by the respiratory syncytial virus (RSV), for the subsequent development of childhood wheezing illness and asthma. Two major hypotheses have been proposed to explain the association between respiratory tract infections and subsequent respiratory abnormalities [68]. One hypothesis states that viral infections early in life damage the growing lung or alter host immune regulation. The second hypothesis holds that respiratory infections are more severe in infants and children with some underlying predisposition. In this case, the symptomatic viral infection is merely an indicator of an otherwise silent condition, whereas viral infections are causal risk factors if the first hypothesis holds true. These two arguments are not mutually exclusive. It is conceivable that severe viral lower respiratory tract infections occur primarily in infants and children with an inherent predisposition, and that both the infection and the predisposition contribute to the development of wheezing illness or other long-term respiratory abnormalities. RSV, in particular, has been shown to induce Th2 responses which may enhance inflammatory changes in susceptible subjects eventually resulting in damage to the airway epithelium and the triggering of asthmatic responses.

Román et al. [69] showed that peripheral blood mononuclear cells (PBMCs) obtained from children hospitalized for RSV had both lower IL-4 and lower IFN- $\gamma$ responses to nonspecific stimuli when compared to the PBMCs of control infants. However, the IFN- $\gamma /$ IL-4 ratios were significantly higher in the control children, suggesting that, although hospitalized infants with RSV may have deficits in both Th-type responses, these deficits are more marked for Th1 than Th2 responses. Similar findings showing increased IL-4 production by the peripheral T-cells of infants with RSV infections have recently been reported [70].

RSV infection is very common in the first year of life. According to LoNG et al. [71], $\geqslant 80 \%$ of all infants are infected with RSV up to their first birthday, but only $\sim 1 \%$ of all infants are hospitalized for RSV disease and only $0.1 \%$ require intensive care. Therefore, a significant proportion of children undergo undetected RSV infections in the first years of life, suggesting that there are one or more host factors which determine the development of bronchiolitis after RSV infection.

Several investigators have followed children with proven RSV bronchiolitis for several years. Most authors [72-74] reported reductions in lung function and increased prevalence of airway hyperresponsiveness in cases as compared to controls, suggesting that RSV infection subsequently leads to airways damage. However, these results are also consistent with the notion of an underlying premorbid respiratory abnormality. PULLEN and HeY [73] followed 130 infants with proven RSV bronchiolitis, who had been admitted to hospital at a mean age of 14 weeks, and compared them with matched controls. Of the RSV group, 6.2\% were wheezing at the age of $10 \mathrm{yrs}$ as compared to $4.5 \%$ of the control group. A slightly increased prevalence of episodic mild wheeze was found during the first 4 yrs of life of the RSV group ( $38 \%$ versus $15 \%$ ), but no increased rate of atopic sensitization was seen in the RSV cases as compared to the controls. Others confirmed these findings [72]. A recent meta-analysis of 10 controlled studies of children hospitalized for RSV bronchiolitis came to the same conclusion. It showed that wheezing was common after RSV bronchiolitis, but that there was no significant difference between the RSV bronchiolitis and the control group regarding recurrent wheezing after $5 \mathrm{yrs}$ of follow-up [74]. A more recent report from a controlled follow-up of 47 infants hospitalized for RSV bronchiolitis up to the age of 7.5 yrs suggested that RSV bronchiolitis may be an independent risk factor for asthma and atopic sensitization at school age $[75,76]$. The population included in this study may, however, have been skewed towards the more severe and more atopic end, thus making it impossible to distinguish an underlying premorbid respiratory abnormality from airway damage resulting from the RSV infection. To avoid this potential severe selection bias, studies in a general population sample are needed to address these questions. Findings from the longitudinal Tucson Birth Cohort Study corroborated the previous observations in a general population sample. In this study, RSV lower respiratory tract illnesses were associated with a diminishing risk of recurrent wheezing over the school years, starting with a 4-fold increased risk at $6 \mathrm{yrs}$, which then reduced to no risk at 13 yrs [77].

\section{Other infections of the respiratory tract}

In several studies, an inverse relationship between asthma and the overall burden of respiratory infections 
has been reported. In Papua New Guinea, ANDERson [78] observed that respiratory infections were more common among young children in the Highlands, where the asthma rate was exceedingly low as compared to the coastal regions of the country where asthma occurred more frequently. In the Fiji Islands, FLYNN [79, 80] studied two groups of children, the indigenous Fijians who showed a high hospital admission rate for pneumonia and the Fiji Indians whose asthma admission rate was three times higher than in the Fijians. Consistent with the hospitalization rates, Indian children had a three-fold higher prevalence of asthma and airway hyperresponsiveness than Fijians, whereas respiratory infections were more than twice as common in Fijian than in Indian children. In the East European countries, a higher prevalence of bronchitis and respiratory infection was found, whereas asthma and bronchial hyperresponsiveness were significantly lower than in Sweden and West Germany [1, 2].

As described earlier, attendance to day care centres early in life is associated with a significant risk of infectious illnesses, among these lower respiratory tract illnesses such as croup, bronchitis, pneumonia and wheezing illnesses. Therefore, in contrast to the potential beneficial effects of early life infections on the development of hay fever and atopy, the inception of asthma may be favoured by such exposures. In fact, several studies have reported that at preschool age the prevalence and incidence of wheezing, lower respiratory tract illnesses was increased in children attending day nurseries. A report from the longitudinal followup of the Tucson cohort has recently reconciled these apparently contradictory findings. The investigators showed that children in day care very early in life (i.e. in the first 6 months of life) were at increased risk of wheezing in the first years of life. This relationship, however, reversed at age $\sim 6$ yrs, by which time attendance to day care early in life had proved to be protective against the occurrence of wheezing illnesses. This beneficial effect increased up to the age of 13 yrs when the risk of wheezing among former day care attendees was less than one-third as compared to other children raised at home. Recent analyses of the German longitudinal Multicentre Allergy Study (MAS) are in line with these findings and suggest that repeated episodes of rhinitis in the first year of life and viral infections of the herpes type in the first $3 \mathrm{yrs}$ of life are associated with a significant decrease in the risk of subsequent wheezing up to the age of 7 yrs [81].

The role of other types of infections in the development of childhood asthma awaits further clarification. Two studies have shown an inverse relationship between asthma and tuberculosis. The ecological analysis of the variation of asthma prevalences over geographical areas as assessed in the ISAAC study, and tuberculosis notification rates, suggest a significant inverse relationship between the occurrence of both diseases at a population level [42]. Likewise, the Finnish study has supported these findings, showing an inverse association between tuberculosis, infections in childhood and the prevalence of asthma 28-32 yrs later [43]. This effect, however, was only seen among females. Animal models of mice strongly support the notion of a protective effect of bacille Calmette-Guérin (BCG) infections on the development of asthma. Several studies have consistently shown that infection with Mycobacterium strongly inhibits an established allergic response and suppresses allergen-induced airway eosinophilia [82-85].

\section{Role of vaccinations and antibiotic use}

Many have speculated about a potential harmful effect of vaccinations and antibiotic use. However, most studies have allayed concerns about an increased risk of atopy and asthma from immunizations with measles, pertussis or other vaccines. About half of the British 1970 birth cohort, >13,000 children, were vaccinated against measles and no substantial difference in the prevalence of hay fever or eczema was evident at the age of 5 yrs when immunized and nonimmunized subjects were compared [86]. Although, in theory, pertussis vaccine or its associated adjuvant may increase $\mathrm{IgE}$ production and thereby the risk of allergy, the results of several epidemiological studies have excluded a major increase in the risk of allergy [87, 88]. Conversely, immunization with BCG, which may induce Th1 responses, has not been shown to confer protection from the development of allergy when administered once early in life [89, 90].

Furthermore, there is no evidence to date to suggest that the use of antibiotics may be causally related to the inception of childhood asthma or allergies. Two recent retrospective studies [91, 92] showing a positive association between antibiotic use and asthma must be interpreted with great caution, since a potential severe bias by reverse causation cannot be excluded, i.e. children with pre-existing symptoms of asthma may receive more antibiotics because of their disease. The recent analysis of the German MAS study supports this notion, finding no association between antibiotic use in the first 3 yrs of life for indications other than lower respiratory tract illnesses and asthma or atopy at the age of 7 yrs [81].

\section{Conclusions}

There is increasing, though still not conclusive, evidence to support the "hygiene hypothesis". The strongest arguments for such an effect are the findings that relate early life day care attendance to a significantly reduced risk of atopy and asthma, and the strong link between sibship size and the occurrence of atopy as confirmed by numerous studies. Furthermore, data relating serological immune responses to certain infections such as hepatitis $\mathrm{A}$ and $T$. gondii suggest a role for such infections or the lack of hygiene to be operative in the inhibition of the development of allergic immune responses. Biological plausibility for such a hypothesis can also be found from recent in vitro studies and from animal experiments. Epidemiological studies attempting to identify single infections as harmful or beneficial could fail because it may be the total burden of microbial stimuli, rather than a certain infection that directs the maturing immune 
system into a T-helper1-polarized response. The effects described in epidemiological studies seem stronger for atopy than for asthma; whereas, in animal models, infections have also been shown to suppress asthmatic features such as airway eosinophilia. The reasons for this apparent discrepancy may be twofold. Firstly, an asthmatic's susceptibility to react to viral infections with lower respiratory tract symptoms will suggest a positive, causal association, where in fact reverse causation is the most likely explanation. Secondly, the timing of the exposure may be essential to promote beneficial or harmful effects. Exposure in the first months of life, before asthma has become evident, may exert protective effects; whereas, infections later in life may trigger symptoms and exacerbate the disease once it is established. The "window of opportunity" for hay fever is likely to increase, as its incidence does not peak in the first 1-4 yrs of life like asthma, but rather in school age and adolescence.

\section{References}

1. ISAAC Steering Committee. Worldwide variations in the prevalence of atopic diseases: the International Study of Asthma and Allergies in Childhood (ISAAC). Lancet 1998; 351: 1225-1232.

2. von Mutius E, Martinez FD, Fritzsch C, Nicolai T, Roell G, Thlemann HH. Prevalence of asthma and atopy in two areas of West and East Germany. Am J Respir Crit Care Med 1994; 149: 358-364.

3. Brabäck L, Breborowicz A, Julge K, et al. Risk factors for respiratory symptoms and atopic sensitisation in the Baltic area. Arch Dis Child 1995; 72: 487-493.

4. Nowak D, Heinrich J, Jörres R, et al. Prevalence of respiratory symptoms, bronchial hyperresponsiveness and atopy among adults: West and East Germany. Eur Respir J 1996; 9: 2541-2552.

5. Martinez FD, Wright AL, Taussig LM, et al. Asthma and wheezing in the first six years of life. $N$ Engl $J$ Med 1995; 332: 133-138.

6. von Mutius E, Nicolai T. Familial aggregation of asthma in a South Bavarian population. Am J Respir Crit Care Med 1996; 153: 1266-1272.

7. Yunginger JW, Reed CE, $\mathrm{O}^{\prime}$ Connell EJ, Melton J, $\mathrm{O}^{\prime}$ Fallon WM, Silverstein MD. A community-based study of the epidemiology of asthma. Incidence rates, 1964-1983. Am Rev Respir Dis 1992; 146: 888-894.

8. Clough JB, Williams JD, Holgate ST. Effect of atopy on the natural history of symptoms, peak expiratory flow, and bronchial responsiveness in 7- and 8-yearold children with cough and wheeze. Am Rev Respir Dis 1991; 143: 755-760.

9. Kelly WJ, Hudson I, Phelan PD, Pain MC, Olinsky A. Atopy in subjects with asthma followed to the age of 28 years. J Allergy Clin Immunol 1990; 85: 548-557.

10. Van Asperen PP, Kemp AS, Mukhi A. Atopy in infancy predicts the severity of bronchial hyperresponsiveness in later childhood. J Allergy Clin Immunol 1990; 85: 790-795.

11. Pearce N, Pekkanen J, Beasley R. How much asthma is really attributable to atopy? Thorax 1999; 54: 268 272.

12. Sigurs N, Hattevig G, Kjellman B, Kjellman N-IM, Nilsson L, Bjöksten B. Appearance of atopic disease in relation to scrum $\operatorname{IgE}$ antibodies in children followed up from birth for 4 to 15 years. J Allergy Clin Immunol 1994; 14: 551-559.

13. Nickel R, Kulig M, Forster J, et al. Sensitisation to hen's egg at the age of twelve months is predictive for allergic sensitisation to common indoor and outdoor allergens at the age of three years. J Allergy Clin Immunol 1997; 99: 613-617.

14. Illi S, von Mutius E, Wahn U and the MAS Study Group. Among asthmatic children atopy starts very early in life. Eur Respir J 1999; 14: S175.

15. von Mutius E. The influence of birth order on the expression of atopy in families: a gene-environment interaction? Clin Exp Allergy 1998; 28: 1454-1456.

16. Ponsonby A-L, Couper D, Dwyer T, Carmichael A. Cross sectional study of the relation between sibling number and asthma, hay fever, and eczema. Arch Dis Child 1998; 79: 328-333.

17. Strachan DP, Taylor EM, Carpenter G. Family structure, neonatal infection, and hay fever in adolescence. Arch Dis Child 1996; 74: 422-426.

18. Strachan DP. Hay fever, hygiene, and household size. BMJ 1989; 299: 1259-1260.

19. Prescott SL, Macaubas C, Smallacombe T, Holt BJ, Sly PD, Holt PG. Development of allergen-specific T-cell memory in atopic and normal children. Lancet 1999; 353: 196-200.

20. Romagnani S. Human TH1 and TH2 subsets: Regulation of differentiation and role in protection and immunopathology. Int Arch Allergy Immunol 1992; 98: 279-285.

21. Parronchi P, De Carli M, Manetti R, et al. IL-4 and IFNs exert opposite regulatory effects on the development of cytolytic potential by Th1 or Th2 human T cell clones. J Immunol 1992; 149: 2977-2983.

22. Maggi E, Parronchi P, Manetti R, et al. Reciprocal regulatory effects of IFN-gamma and IL-4 on the in vitro development of human Th1 and Th2 clones. J Immunol 1992; 148: 2142-2147.

23. Humbert M, Menz G, Ying S, et al. The immunopathology of extrinsic (atopic) and intrinsic (nonatopic) asthma: more similarities than differences. Immunol Today 1999; 20: 528-533.

24. Herz U, Bunikowski R, Renz H. Role of $\mathrm{T}$ cells in atopic dermatitis. Int Arch Allergy Immunol 1998; 115: 179-190.

25. Hamid Q, Boguniewicz M, Leung DYM. Differential in situ cytokine gene expression in acute versus chronic atopic dermatitis. J Clin Invest 1994; 94: 870-876.

26. Gern JE, Weiss ST. Protection against atopic diseases by measles - a rash conclusion? JAMA 2000; 283: 394 395.

27. Nafstad P, Hagen JA, Oie L, Magnus P, Jaakkola JJK. Day care centers and respiratory health. Pediatrics 1999; 103: 753-758.

28. Celedon JC, Litonjua AA, Weiss ST, Gold DR. Day care attendance in the first year of life and illnesses of the upper and lower respiratory tract in children with a familial history of atopy. Pediatrics 1999; 104: 495500 .

29. Marbury MC, Maldonado G, Waller L. Lower respiratory illness, recurrent wheezing, and day care attendance. Am J Respir Crit Care Med 1997; 155: $156-161$.

30. Krämer U, Heinrich J, Wjst M, Wichmann H-E. Age of entry to day nursery and allergy in later childhood. Lancet 1999; 353: 450-454. 
31. Ball TM, Castro-Rodriguez JA, Griffith KA, Holberg CJ, Martinez FD, Wright AL. Siblings, day-care attendance, and the risk of asthma and wheezing during childhood. $N$ Engl J Med 2000; 343: 538-543.

32. Matricardi PM, Rosmini F, Ferrigno L, et al. Cross sectional retrospective study of prevalence of atopy among Italian military students with antibodies against hepatitis A virus. BMJ 1997; 314: 999-1003.

33. Shaheen SO, Aaby P, Hall AJ, et al. Measles and atopy in Guinea-Bissau. Lancet 1996; 347: 1792-1796.

34. Alm JS, Swartz J, Lilja G, Scheynius A, Pershagen G. Atopy in children of families with an anthroposophic lifestyle. Lancet 1999; 353: 1485-1488.

35. Paunio M, Hemonen OP, Virtanen M, Leinikki P, Patja A, Peltola H. Measles history and atopic diseases. A population-based cross-sectional study. JAMA 2000; 283: 343-346.

36. Bodner C, Godden D, Seaton A. Family size, childhood infections and atopic diseases. The Aberdeen WHEASE Group. Thorax 1998; 53: 28-32.

37. Lewis SA, Britton JR. Measles infection, measles vaccination and the effect of birth order in the aetiology of hay fever. Clin Exp Allergy 1998; 28: 1493-1500.

38. Schluger NW, Rom WN. The host immune response to tuberculosis. Am J Respir Crit Care Med 1998; 157: 679-691.

39. Orme IM, Andersen P, Boom WH. T cell response to Mycobacterium tuberculosis. J Infect Dis 1993; 167: 1481-1497.

40. Shirakawa T, Enomoto T, Shimazu S, Hopkin JM. The inverse association between tuberculin responses and atopic disorder. Science 1997; 275: 77.

41. Hovmark A. An in vivo and in vitro study of cellmediated immunity in atopic dermatitis. Acta Dermatovenerol 1975; 55: 181-186.

42. von Mutius E, Pearce N, Beasley R, et al. International patterns of tuberculosis and the prevalence of symptoms of asthma, rhinitis, and eczema. Thorax 2000; 55: 449-453.

43. von Hertzen L, Klaukka T, Mattila H, Haalitela T. Mycobacterium tuberculosis infection and the subsequent development of asthma and allergic conditions. J Allergy Clin Immunol 1999; 104: 1211-1214.

44. Martinez FD, Stern DA, Wright AL, Taussig LM, Halonen $\mathrm{M}$ and GHM Associates. Association of non-wheezing lower respiratory tract illnesses in early life with persistently diminished serum $\operatorname{IgE}$ levels. Thorax 1995; 50: 1067-1072.

45. Matricardi PM, Rosmini F, Riondino S, et al. Exposure to foodborne and orofecal microbes versus airborne viruses in relation to atopy and allergic asthma: epidemiological study. BMJ 2000; 320: 412417.

46. Stein RT, Sherrill D, Morgan WJ, et al. Respiratory syncytial virus in early life and risk of wheeze and allergy by age 13 years. Lancet 1999; 354: 541-545.

47. Wold AE. The hygiene hypothesis revised: is the rising frequency of allergy due to changes in the intestinal flora? Allergy 1998; 53: Suppl. 46, 20-25.

48. Holt PG. Mucosal immunity in relation to the development of oral tolerance/sensitization. Allergy 1998; 53: Suppl. 46, 16-19.

49. Sepp E, Julge K, Vasar M, Naaber P, Björkstén B, Mikelsaar M. Intestinal microflora of Estonian and Swedish infants. Acta Paediatr 1997; 86: 956-961.

50. Björkstén B, Naaber P, Sepp E, Mikelsaar M. The intestinal microflora in allergic Estonian and Swedish 2-year-old children. Clin Exp Allergy 1999; 29: 342346.

51. Majamaa H, Isolauri E. Probiotics: a novel approach in management of food allergy. $J$ Allergy Clin Immunol 1997; 99: 179-185.

52. Dold S, Heinrich J, Wichmann HE, Wjst M. Ascarisspecific IgE and allergic sensitization in a cohort of school children in the former East Germany. $J$ Allergy Clin Immunol 1998; 102: 414-420.

53. Braun-Fahrländer $\mathrm{Ch}$, Gassner $\mathrm{M}$, Grize $\mathrm{L}$, et al. Prevalence of hay fever and allergic sensitization in farmer's children and their peers living in the same rural community. Clin Exp Allergy 1999; 29: 28-34.

54. von Ehrenstein O, von Mutius E, Illi S, Baumann L, Böhm O, von Kries R. Reduced risk of hay fever and asthma among children of farmers. Clin Exp Allergy 2000; 30: 187-193.

55. Riedler J, Eder W, Oberfeld G, Schreuer M. Austrian children living on a farm have less hay fever, asthma and allergic sensitisation. Clin Exp Allergy 2000; 30: 194-200.

56. von Mutius E, Braun-Fahrländer C, Schierl R, et al. Exposure to endotoxin or other bacterial components might protect against the development of atopy. Clin Exp Allergy 2000; 30: 1230-1234.

57. Rietschel ET, Schade U, Jensen M, Wollenweber HW, Lüderitz O, Greisman SG. Bacterial endotoxins: chemical structure, biological activity, and role in septicaemia. Scand J Infect Dis Suppl 1982; 31: 8-21.

58. Martinez FD. Maturation of immune responses at the beginning of asthma. J Allergy Clin Immunol 1999; 103: 355-361.

59. Macatonia SE, Hosken NA, Litton M, et al. Dendritic cells produce IL-12 and direct the development of Th1 cells from naive CD4+ T cells. J Immunol 1995; 154: 5071-5079.

60. Michel O, Ginanni R, Duchateau J, Vertongen F, Le Bon B, Sergysels R. Domestic endotoxin exposure and clinical severity of asthma. Clin Exp Allergy 1991; 21: 441-448.

61. Hesselmar B, Aberg N, Aberg B, Eriksson B, Björkstén B. Does early exposure to cat or dog protect against later allergy development? Clin Exp Allergy 1999; 29: 611-617.

62. Svanes C, Jarvis D, Chinn S, Burney P. Childhood environment and adult atopy: results from the European Community Respiratory Health Survey. J Allergy Clin Immunol 1999; 103: 415-420.

63. Abou-Zeid C, Gares MP, Inwald J, et al. Induction of a type 1 immune response to a recombinant antigen from Mycobacterium tuberculosis expressed in Mycobacterium vaccae. Infect Immun 1997; 65: 1856-1862.

64. Cleveland MG, Gorham JD, Murphy TL, Toumanen E, Murphy KM. Lipoteichoic acid preparations of gram-positive bacteria induce interleukin-12 through a CD14-dependent pathway. Infect Immun 1996; 64 : 1906-1912.

65. Yeung VP, Gieni RS, Umetsu DT, DeKruyff RH. Heat-killed Listeria monocytogenes as an adjuvant converts established murine Th2-dominated immune responses into Th1-dominated responses. J Immunol 1998; 161: 4146-4152.

66. Jahn-Schmid B, Wiedermann U, Bohle B, Repa A, Kraft D, Ebner C. Oligodeoxynucleotides containing $\mathrm{CpG}$ motifs modulate the allergic Th2 response of 
$\mathrm{BALB} / \mathrm{c}$ mice to Bet $\mathrm{v} 1$, the major birch pollen allergen. J Allergy Clin Immunol 1999; 104: 1015-1023.

67. Gereda JE, Leung DYM, Thatayatikom A, et al. Relation between house-dust endotoxin exposure, type 1 T-cell development, and allergen sensitisation in infants at high risk of asthma. Lancet 2000; 355: $1680-1683$.

68. Price JF. Acute and long-term effects of viral bronchiolitis in infancy. Lung 1990; 168: Suppl. 414 421.

69. Román M, Calboun WJ, Hinton KL, et al. Respiratory syncytial virus infection in infants is associated with predominant Th-2-like response. Am J Respir Crit Care Med 1997; 156: 190-195.

70. Bendelja K, Gagro A, Bace A, et al. Predominant type-2 response in infants with respiratory syncytial virus (RSV) infection demonstrated by cytokine flow cytometry. Clin Exp Immunol 2000; 121: 332-338.

71. Long CE, McBride JT, Hall CB. Sequelae of respiratory syncytial virus infections. A role for intervention studies. Am J Respir Crit Care Med 1995; 151: 1678-1681.

72. Sims D, Downham M, Gardner P, Webb J, Weightman D. Study of 8 year old children with a history of RSV bronchiolitis in infancy. BMJ 1978; 1: 11-14.

73. Pullen CR, Hey EN. Wheezing, asthma and pulmonary dysfunction 10 years after infection with respiratory syncytial virus in infancy. $B M J 1982 ; 284$ : $1665-1669$.

74. Kneyber MCJ, Steyerberg EW, de Groot R, Moll HA. Long-term effects of respiratory syncytial virus (RSV) bronchiolitis in infants and young children: a quantitative review. Acta Paediatr 2000; 89: 654-660.

75. Sigurs N, Bjarnason R, Sigurbergsson F, Kjellman B, Björksten B. Asthma and immunoglobulin E antibodies after respiratory syncytial virus bronchiolitis: a prospective cohort study with matched controls. Pediatrics 1995; 95: 500-505.

76. Sigurs N, Bjarnason R, Sigurbergsson F, Kjellman B. Respiratory syncytial virus bronchiolitis in infancy is an important risk factor for asthma and allergy at age 7. Am J Respir Crit Care Med 2000; 161: 1501-1507.

77. Stein RT, Sherrill D, Morgan WJ, et al. Respiratory syncytial virus in early life and risk of wheeze and allergy by age 13 years. Lancet 1999; 354: 541-545.

78. Anderson HR. The epidemiological and allergic features of asthma in the New Guinea Highlands. Clin Allergy 1974; 4: 171-183.

79. Flynn MGL. Respiratory symptoms, bronchial responsiveness, and atopy in Fijan and Indian children. Am J Respir Crit Care Med 1994; 150: 415420.

80. Flynn MGL. Respiratory symptoms of rural Fijian and Indian children in Fiji. Thorax 1994; 49: 12011204.

81. Illi S, von Mutius E, Bergmann $\mathrm{R}$, et al. Upper respiratory tract infections in the first year of life and asthma in children up to the age of 7 years. $\mathrm{Am}$ J Respir Crit Care Med 2000; 161: A704.

82. Erb KJ, Holloway JW, Sobeck A, Moll H, Le Gros G. Infection of mice with Mycobacterium bovis-Bacillus Calmette-Guérin (BCG) suppresses allergen-induced airway eosinophilia. J Exp Med 1998; 187: 561-569.

83. Herz U, Gerhold K, Gruber C, et al. BCG infection suppresses allergic sensitization and development of increased airway reactivity in an animal model. J Allergy Clin Immunol 1998; 102: 867-874.

84. Wang CC, Rook GAW. Inhibition of an established allergic response to ovalbumin in BALB/e mice by killed Mycobacterium vaccae. Immunology 1998; 93: 307-313.

85. Yang X, Wang S, Fan Y, Zhu L. Systemic mycobacterial infection inhibits antigen-specific immunoglobulin E production, bronchial mucus production and eosinophilic inflammation induced by allergen. Immunology 1999; 98: 329-337.

86. Strachan DP. Family size, infection and atopy: the first decade of the "hygiene hypothesis". Thorax 2000; 55: Suppl. 1, S2-S10.

87. Henderson J, North K, Griffiths M, Harvey I, Golding J. Pertussis vaccination and wheezing illnesses in young children: prospective cohort study. The Longitudinal Study of Pregnancy and Childhood Team. BMJ 1999; 318: 1173-1176.

88. Nilsson L, Kjellman NIM, Björksten B. A randomized controlled trial of the effect of pertussis vaccines on atopic disease. Arch Pediatr Adolesc Med 1998; 152: 734-738.

89. Strannegard IL, Larsson LO, Wennergren G, Strannegard O. Prevalence of allergy in children in relation to prior $\mathrm{BM}$ vaccination and infection with atypical mycobacteria. Allergy 1998; 53: 249-254.

90. Alm JS, Lilja G, Pershagen G, Scheynius A. Early $\mathrm{BCG}$ vaccination and development of atopy. Lancet 1997; 350: 400-403.

91. Farooqi IS, Hopkin M. Early childhood infection and atopic disorder. Thorax 1998; 53: 927-932.

92. Wickens K, Pearce N, Crane J, Beasley R. Antibiotic use in early childhood and the development of asthma. Clin Exp Allergy 1999; 29: 766-771. 